\title{
Improvement in GRS Compressor System to Increase Reliability of Combined Cycle Power Plant PT. PJB UP Muara Tawar
}

\author{
Willy Prasetyo Adi ${ }^{1}$, Jhon Arcidma ${ }^{1}$, Muhammad Roshie Friansyah ${ }^{1}$, \\ Kevin Sanjoyo Gunawan ${ }^{2}$, Totok R. Biyanto ${ }^{2 *}$ \\ ${ }^{I}$ PT. PJB UP Muara Tawar, Muara Tawar, Indonesia \\ ${ }^{2}$ Engineering Physics Department, Institut Teknologi Sepuluh Nopember (ITS), Surabaya, Indonesia.
}

\begin{abstract}
Fuel gas is the main fuel used in PT PJB UP Muara Tawar combined cycle power plant. Reliability of combinend cycle power plant can be affected with fluctuative supply of fuel gas. Fuel gas supplied by PGN with pressure range 24-26 barG. Because of fluctuative pressure from supplier, pressure of gas must be adjusted by using Gas Receiving Station (GRS) system. There are HMI local panel in GRS as interface. HMI local panel consist of bypass system and fuel gas compressor system. Bypass system used to decrease gas pressure when gas pressure above the upper limit while compressor used to increase gas pressure when gas pressure under lower limit. GRS have an important role in operational Block 5 PT PJB UP Muara Tawar. In 9 December 2011-26 Januari 2015 period, Block 5 can not be operated because of mechanical seal failure in fuel gas compressor in GRS. Ordering new seal has take a long time. GRS can not be operated when compressor gas fail due to fluctuatif pressure of supplied gas. Moreover, GRS has far distance from main control room (MCR). It will be difficult to monitor GRS parameter from control room. By this problem, research and improvement in GRS should be done so that performance of GRS can be improved. Improvement in low limit fuel gas pressure was performed. By this changing, inlet pressure GT operation has wider range. In addition, making $1 \mathrm{~K}$ changeover can increase GRS performance. The addition of overview, parameters, alarm indicators on Alspa HMI can improve the reliability of the operation of Gas Turbine because the operator can respond faster when there is a change of parameters in GRS.
\end{abstract}

Keywords: CCPP, Compressor, GRS, HMI, Reliability

\section{Introduction}

Fuel gas is the main fuel used in PT PJB UP Muara Tawar combined cycle power plant [1]. Reliability of combined cycle power plant can be affected with fluctuate supply of fuel gas [2]. Fuel gas supplied by Perusahaan Gas Negara (PGN) have pressure range 24-26 barG. Due to fluctuate pressure from supplier, pressure of gas must be adjusted by using Gas Receiving Station (GRS) system [3]. There are HMI local panel in GRS as interface [4]. HMI local panel consist of bypass system and fuel gas compressor system [5]. Bypass system is used to decrease gas pressure when gas pressure above the upper limit while compressor is used to increase gas pressure when gas pressure under lower limit. GRS have an important role in operational Block 5 PT PJB UP Muara Tawar.

In 9 December 2011-26 January 2015 period, Block 5 cannot be operated because of mechanical seal failure in fuel gas compressor in GRS. Ordering new seal has took a long time. GRS cannot be operated when compressor gas fail due to fluctuate pressure of supplied gas. Moreover, GRS has far distance from main control room (MCR). It will be difficult to monitor GRS parameter from control room. By this problem, research and improvement in GRS should be done so that performance of GRS can be improved [6,7].

\section{Theory}

Gas Receiving Station (GRS) consist of Compressor System and Bypass System. If fuel gas pressure is too high, fuel gas will flow through bypass system to reduce the pressure. If fuel gas pressure too low, compressor gas is used to increase fuel gas pressure. Bypass System consist of two main pipe with control valve position always 50\%. Control valve in bypass system will close automatically if pressure above 34 barG. In other hand, fuel Gas Compressor System will start if fuel gas pressure below the low limit. Fuel Gas Compressor System specification is shown in Table 1: 
Table 1. Fuel Gas Compressor Specification

\begin{tabular}{|c|c|c|c|c|}
\hline \multirow[b]{2}{*}{ Compressor Operating Case } & \multirow[b]{2}{*}{ Unit } & \multicolumn{3}{|c|}{ Design at min suction pressure } \\
\hline & & A & B & c \\
\hline $\begin{array}{l}\text { Inlet hrensure at terminal point of } \\
\text { supply. }\end{array}$ & thara & 13 & 13 & 13 \\
\hline Fow tate & $\mathrm{kg} / \mathrm{s}$ & 9.46 & 10.13 & 9.59 \\
\hline Fel gas iniat Temp of int of supply & $\propto$ & 30 & 24 & 48.2 \\
\hline Deschorge Pressuit: & Barn & 28.5 & 28.5 & 285 \\
\hline Shah Nower & $\overline{W W}$ & 1952 & 1972 & 1930 \\
\hline Power consumpton asix & KW & Gater & tater & Later \\
\hline Max dacharge presulare gradient" & bat/s & 0.2 & 0.2 & 0.2 \\
\hline \multicolumn{5}{|l|}{ Max dicchargo nuktuation for : } \\
\hline Transient Operation & $\%$ & $+l-5$ & $+1-5$ & $+/ 5$ \\
\hline Stedfy State Operation & \% & $+1-2$ & +2 & $+\sqrt{-2}$ \\
\hline Max gas fischarge temp & ${ }^{\circ} \mathrm{C}$ & 100 & 100 & 100 \\
\hline Max allowable working ginsteves & Bark & 35.5 & 35.5 & 35.5 \\
\hline
\end{tabular}

Fexcept for SEV trip; GT load rejection \& GT trip

\subsection{Identification}

\section{Method}

Based on historical data from operational in 9 December 2011 there are GT trip due to mechanical seal problem in gas compressor. GT cannot be operated until 26 January 2012. Fluctuate pressure of supplied gas (24-26 barG) make impossible GT operation without gas compressor. Bypass system itself can be operated if gas pressure reach 27 barG so without gas compressor it will be impossible to start GT operation due to fluctuate gas supply. Therefore, improvement in low pressure limit for GT inlet must be reviewed.

Table 2. Initial Condition Protection List Gas Pressure Too Low

\begin{tabular}{|c|c|c|c|c|c|c|}
\hline No & $\begin{array}{l}\text { PIS5.4.4: Cas } \\
\text { Pressure Too } \\
\text { Low }\end{array}$ & KKS : & $\begin{array}{l}\text { Protective } \\
\text { Actione }\end{array}$ & Limits & $\begin{array}{l}\text { Activation } \\
\text { Redundancy }\end{array}$ & $\begin{array}{l}\text { Acthration } \\
\text { Detiny }\end{array}$ \\
\hline 2 & $\begin{array}{l}\text { he5.4.4.2 } \\
\text { Pressure too low } \\
\text { upstream gas } \\
\text { conteol valee } \\
\text { dunng opericion }\end{array}$ & МВМОСО01 & Alarm & $\begin{array}{l}-21.18 \\
\text { hort }\end{array}$ & loot andiog & 0 ese \\
\hline 2 & $\begin{array}{l}\text { 175.4.4.1 } \\
\text { Pressure too bw } \\
\text { upotream gas } \\
\text { contras value } \\
\text { durmg operation }\end{array}$ & МIPASOCPOOL & PLST & $\begin{array}{l}223.3 \\
\text { bar6 }\end{array}$ & icel arabs & $6 \mathrm{sec}$ \\
\hline
\end{tabular}

Reference for protection list GT block 5 can be obtained by GT block 1 as comparison. GT block 1 has same type with GT block 5 however GT block 1 has better protection list compared to GT block 5 .

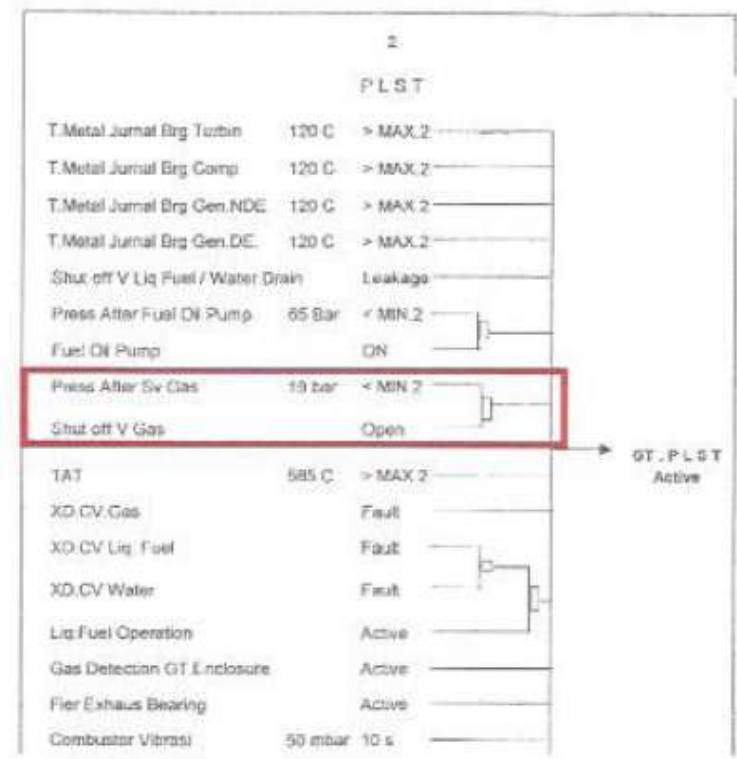

Figure 1. Protection List PLST Block 1 


\subsection{Problem Solving}

From protection list GT block 1, can be known that low limit fuel gas pressure is 19 barG. Therefore, it is necessary to recalculate the low limit fuel gas pressure inlet for GT Blok 5. Pressure drop calculation used to recalculate low limit fuel gas pressure. New setting for low limit fuel gas pressure is performed with agreement from vendor.

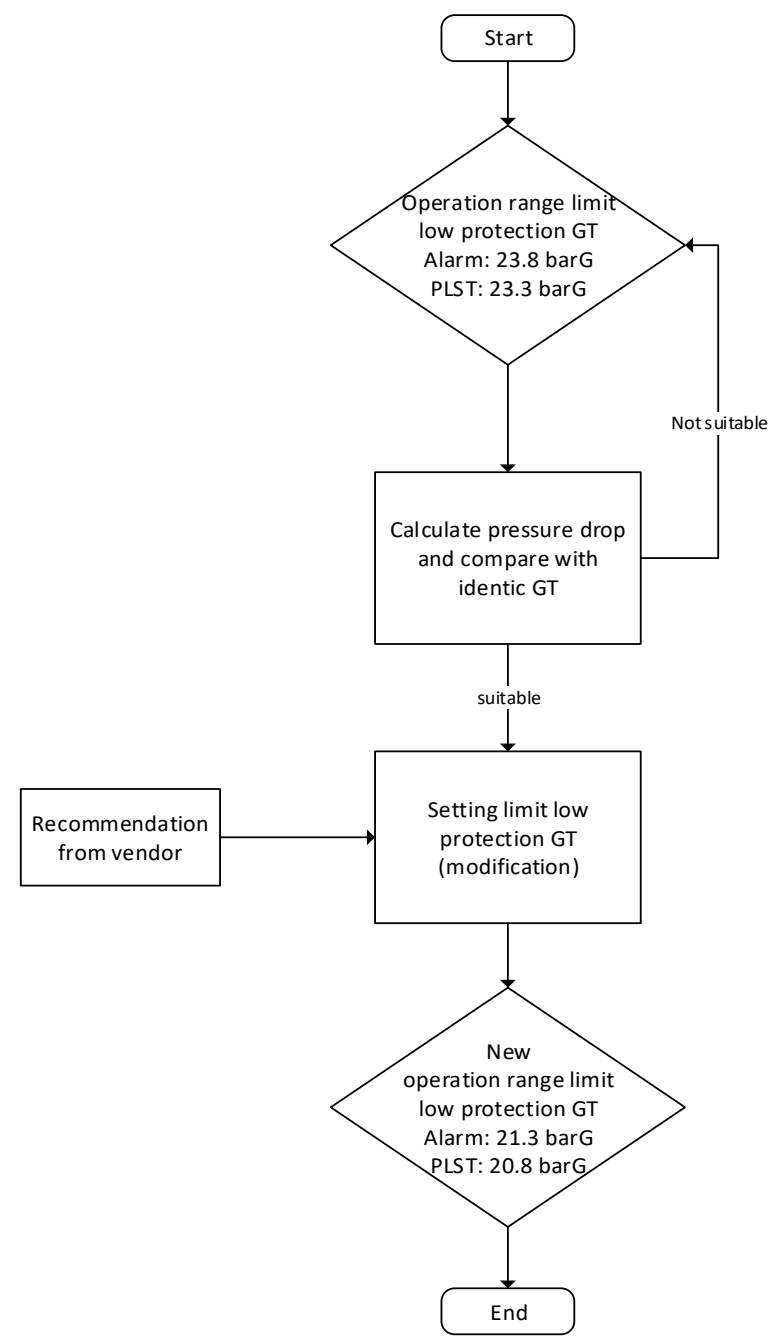

Figure 2. Flowchart Low Limit Fuel Gas Pressure Inlet GT Setting

New setting for low limit fuel gas pressure applied in 26 January 2012. Low limit for fuel gas pressure are reduced so that bypass system can be operate using default pressure from supplier (24-26 barG). Table 3 shows new parameter setting for GT block 5.

Table 3. New Setting Parameter Fuel Gas Pressure Too Low

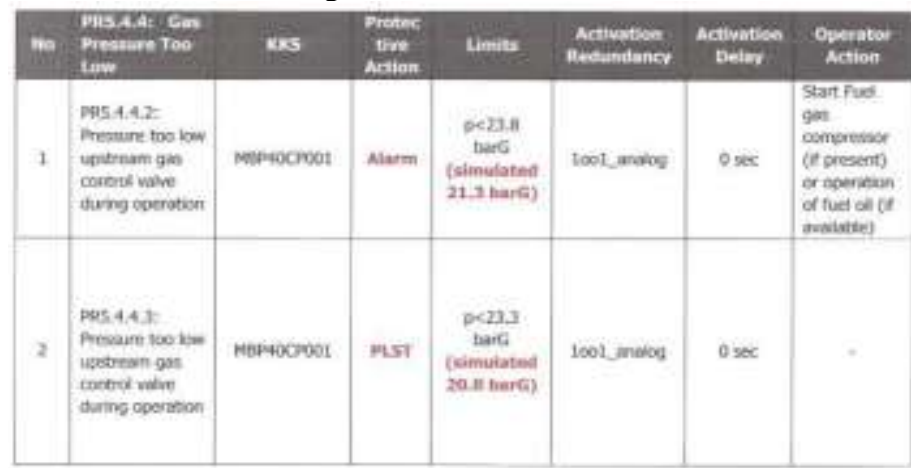


From Table 3. protection load shedding trip (PLST) occur when inlet gas pressure below 20.8 barG and alarm active when pressure below 21.3 barG.

\section{Discussion}

If pressurised gas from supplier above low limit of minimum setting requirement for compressor, the gas from supplier can be used directly into gas turbine. Change in parameter resulted in wider range of inlet pressure GT operation as shown in Figure 3.

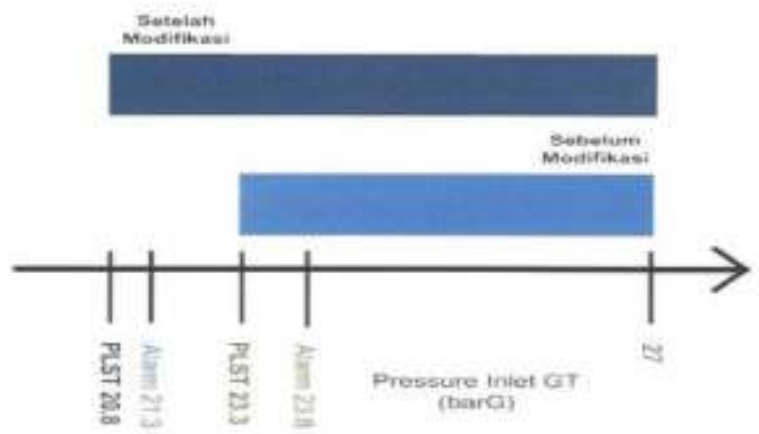

Figure 3. New Operational Range

However, improvement still needed to increase performance of GRS operational as follows

1. Additional overview, parameter and alarm in HMI Alspa (in main control room) shown in Figure 4-6 for better monitoring because GRS to main control room distance is too far.

2. Additional $1 \mathrm{~K}$ changeover from compressor load to bypass system and from bypass system to compressor load to increase system safety.

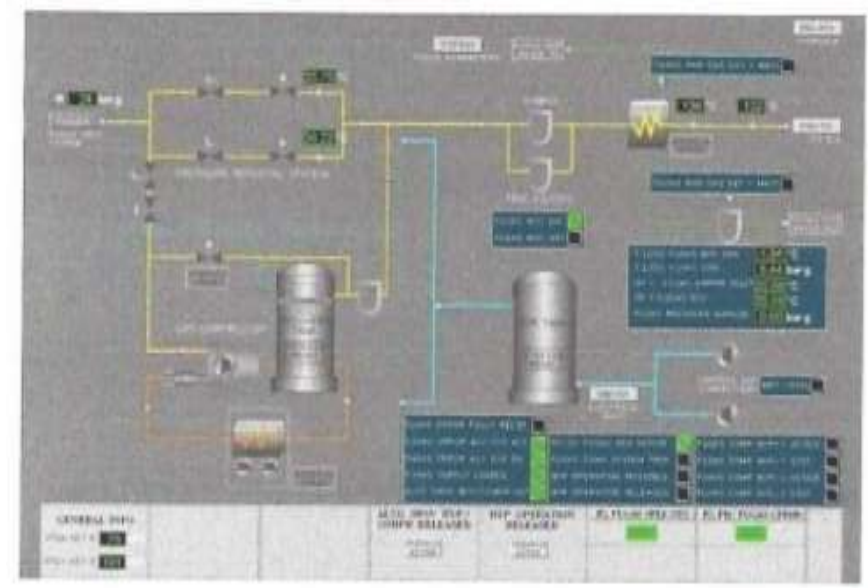

Figure 4. Overview Alspa HMI 51EKB32

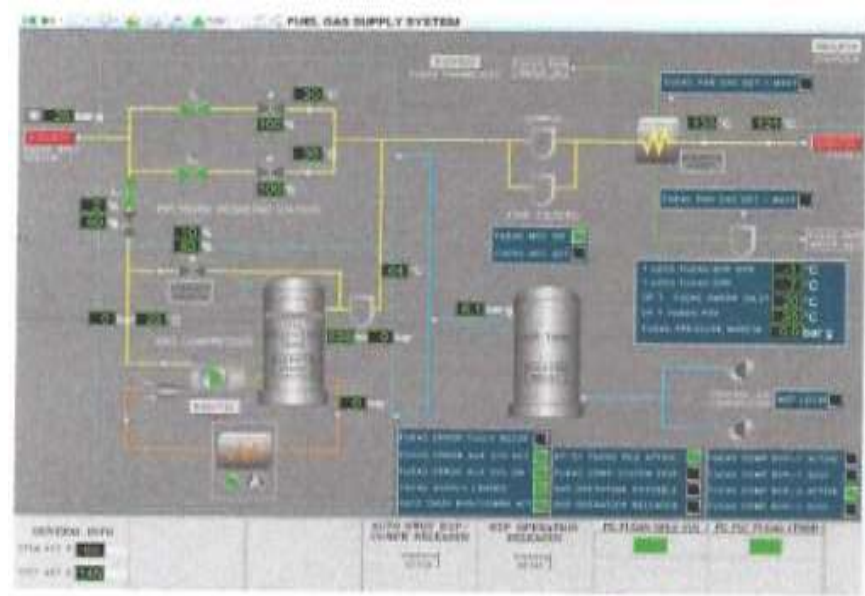

Figure 5. Overview OF HMI Alspa 51EKB32 Modification. 


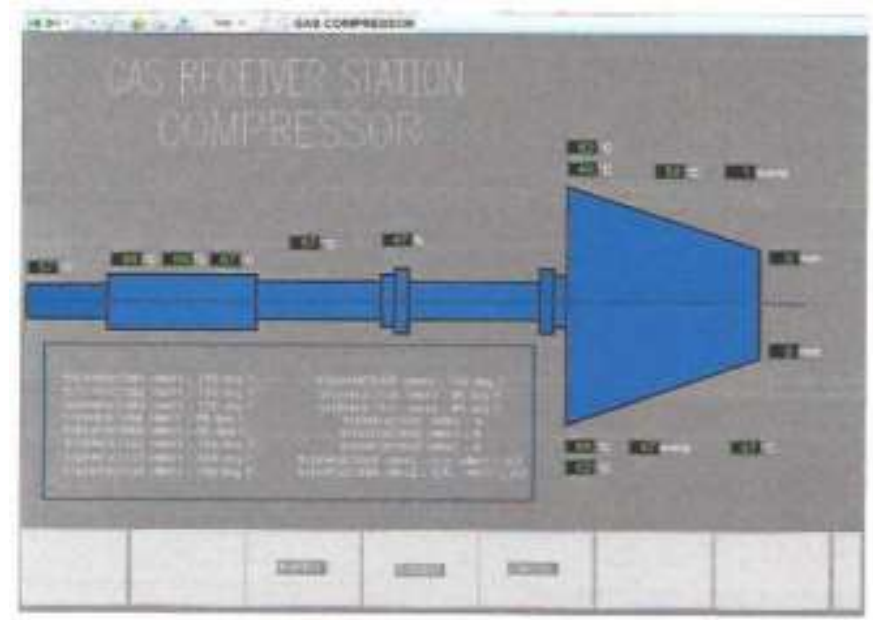

Figure 6. Overview of HMI Alspa 51EKT32 Loop

\section{Conclusion}

Improvement in low limit fuel gas pressure was performed. By this changing, inlet pressure GT operation has wider range. In addition, making $1 \mathrm{~K}$ changeover can increase GRS performance. The addition of overview, parameters, and alarm indicators on Alspa HMI can improve the reliability of the operation gas turbine due to faster respond by operator when there is a change of parameters in GRS.

\section{Acknowledgement}

The authors gratefully thank to PT. PJB UP Muara Tawar - Indonesia for providing the facilities in conducting this research.

\section{References}

[1]. J. G. Speight, Natural Gas-A Basic Handbook, Texas, USA: Gulf Publishing Company, 2007.

[2]. A. Sieminski, "International Energy Outlook," US Energy Information Administration, Washington DC, 2013.

[3]. A. M. Razak, Industrial gas turbines performance and operability, Cambridge: Woodhead Publishing Limited, 2007.

[4]. M. Rasmussen and K. Laumann, "Potential use of HMI evaluation methods in HRA," in 6th International Conference on Applied Human Factors and Ergonomics (AHFE 2015) and the Affiliated Conferences, AHFE 2015, 2015.

[5]. W. Kostowski, "The possibility of energy generation within the conventional natural gas transport system," Theory Application Mechanical Engineering, vol. 52, no. 4, pp. 429-440, 2010

[6]. N. Meshkati, "Organization \& Environment," 1991, pp. 133-154.

[7]. M. Naeem, R. Singh and D. Probert, "Implications of engine deterioration for creep life," Applied Energy, vol. 60, pp. 183-223, 1998. 